\title{
The Maternal Postpartum Quality of Life Instrument (MPQOLI): Development and Psychometric Evaluation in an Exploratory Sequential Mixed- Method Study
}

\section{Tahereh Mokhtarian-Gilani}

Shahid Beheshti University of Medical Sciences School of Nursing and Midwifery

Nourossadat Kariman ( $\sim$ n_kariman@yahoo.com )

Shahid Beheshti University of Medical Sciences, Midwifery and Reproductive Health Research Center https://orcid.org/0000-0001-8413-7175

Hamid Sharif Nia

Mazandaran University of Medical Sciences

Mahbobeh Ahmadi Doulabi

Shahid Beheshti University of Medical Sciences School of Nursing and Midwifery

Malihe Nasiri

Shahid Beheshti University of Medical Sciences School of Nursing and Midwifery

\section{Research}

Keywords: Quality of life, Instrument development, Psychometric assessment, Postpartum period, Validity, and Reliability

Posted Date: January 26th, 2021

DOl: https://doi.org/10.21203/rs.3.rs-152709/v1

License: (c) (i) This work is licensed under a Creative Commons Attribution 4.0 International License. Read Full License 


\title{
The Maternal Postpartum Quality of Life Instrument (MPQOLI): development and psychometric evaluation in an exploratory sequential mixed-method study
}

\author{
Tahereh Mokhtarian-Gilani $^{1}$, Nourossadat Kariman ${ }^{2 *}$, Hamid Sharif Nia ${ }^{3}$, Mahbobeh
}

Ahmadi Doulabi ${ }^{4}$,Malihe Nasiri ${ }^{4}$

${ }^{1}$ PhD. Candidate in Reproductive Health, Midwifery and Reproductive Health Department, School of Nursing
and Midwifery, Shahid Beheshti University of Medical Sciences, Tehran, Iran
${ }^{2}$ Associate Professor, Midwifery and Reproductive Health Research Center, Midwifery and Reproductive
Health Department, School of Nursing and Midwifery, Shahid Beheshti University of Medical Sciences, Tehran,
Iran.
${ }^{3}$ Associate Professor, School of Nursing and Midwifery, Mazandaran University of Medical Sciences, Sari,
Iran.
${ }^{4}$ Assistant Professor, School of Nursing and Midwifery, Shahid Beheshti University of Medical Sciences,
Tehran, Iran

(Corresponding Author*) Nourossadat Kariman: Associate Professor, Midwifery and Reproductive Health Research Center, School of Nursing and Midwifery, Shahid Beheshti University of Medical Sciences, Tehran, Iran; Address: Vali-Asr Avenue, Vali-Asr and Neiaiesh Highway Intersection, Opposite Rajaee Heart Hospital; P.O. Box: 1996835119, Tehran, IR Iran; Tel/Fax: +98 218820 2516, +98 218820 2512; Email:

n_kariman@sbmu.ac.ir,n_kariman@yahoo.com

Support: Shaheed Beheshti Vice-chancellor for Research and Technology 


\begin{abstract}
Background and Objective: There is no comprehensive instrument for the assessment of postpartum quality of life (QOL). This study was conducted to develop the Maternal Postpartum Quality of Life Instrument (MPQOLI) and assess its psychometric properties.

Materials and Methods: This methodological study was conducted in 2019-2020 using an exploratory sequential mixed-method design. A qualitative study and a literature review were conducted to generate MPQOLI items. Through purposeful sampling, 590 postpartum women were recruited to respond the instrument. Face and content validity were assessed qualitatively and quantitatively and construct validity was assessed through exploratory and confirmatory factor analyses and convergent and discriminant validity assessments. Reliability was also assessed through different methods, including Cronbach's alpha and McDonald's Omega.

Results: Eight items were deleted in content validity assessments and eighteen items were deleted in item analysis. Participants responded the 31-item MPQOLI. During exploratory factor analysis, fifteen items were deleted and the remaining sixteen items were loaded on five factors labeled perceived support, sexual relationship, bonding with newborn, breastfeeding and newborn care, and satisfaction with postpartum transition. These five factors explained $53.26 \%$ of the total variance. Confirmatory factor analysis confirmed the five-factor structure of MPQOLI with a CMIN/DF of 2.192, an RMSEA of 0.057, a $\chi 2$ of 206.087, a PCFI of 0.738, a PNFI of 0.705 , a CFI of 0.942 , and an IFI of 0.943 . Average variance extracted was more than 0.5 and more than maximum shared squared variance, confirming convergent and discriminant validity, respectively. Reliability was also confirmed with Cronbach's alpha values of $0.70-0.907$ and an intraclass correlation coefficient of 0.919 .
\end{abstract}

Conclusion: The sixteen-item MPQOLI is a valid and reliable instrument for postpartum QOL assessment. It includes items on the different aspects of postpartum QOL and can be used for the early diagnosis of impaired postpartum QOL. Further studies are needed to assess the psychometric properties of MPQOLI in different cultures and communities.

Keywords: Quality of life, Instrument development, Psychometric assessment, Postpartum period, Validity, and Reliability

\title{
Highlights
}

MPQOLI is a comprehensive instrument with small number of items in the most important dimensions of postpartum QOL.

The psychometric properties of MPQOLI were assessed and confirmed using advanced psychometric assessment methods. 


\section{Introduction}

Giving birth is a unique life experience consisting of subjective physiological and psychological processes affected by social, environmental, organizational, and policy contexts (1). In 2019, the number of daily and annual birth in the world was 385000 and 140008930 , respectively. In Iran, these numbers were 4444 and 1524490, respectively (2). Labor and birth are positive experiences for most women and they usually talk about their labor- and birthrelated experiences with interest and happiness (3). Nonetheless, some women have fears over birth (3).

During the postpartum period, i.e. from one hour to six months after birth, the body of women returns to its pre-pregnancy physiological and anatomical conditions (4). This process is associated with many different psychosocial changes and different new roles which may in turn cause challenges for women in coping, reduce their time for their partner, children, and themselves, and lead to disturbances in daily life (5). Ineffective postpartum coping can cause some postpartum complications and may reduce maternal quality of life (QOL) (6).

QOL refers to an individual's perception of life based on the existing cultural conditions, values, attitudes, goals, and standards (7). According to the World Health Organization, QOL has six main components, namely physical health, psycho-emotional status, level of independence, social relationships, spiritual beliefs, and environmental status. QOL also determines the positive and negative characteristics of life and includes satisfaction with physical health, family, education, employment, possessions, financial status, environment, and religious beliefs (8). QOL is directly affected by the immediate sociocultural context (9). Factors reducing postpartum QOL include inadequate social support, heavy workload, husband's limited engagement in household affairs (10), financial problems, fatigue (11), postpartum depression (12), sexual dysfunction (13), and pregnancy-related complications (14). Sociodemographic and clinical factors can also affect perceived postpartum QOL (15). These factors include age, marital status, educational level, and level of social support (10). Other factors affecting postpartum QOL are the number of pregnancies and the route of delivery (vaginal, elective Cesarean section, or emergency Cesarean section) (10). Reduced postpartum QOL can negatively affect women's childrearing behaviors and children's health (15).

Improvement of QOL and health is a main health-related challenge of the 21th century (16). The most basic step to develop effective plans for postpartum QOL improvement is careful postpartum QOL assessment (17) so that postpartum QOL assessment has turned into an inseparable part of postpartum care (18). Such assessment can provide reliable data about women's postpartum conditions and helps develop effective plans for improving their conditions (19).

There are limited instruments for postpartum QOL assessment. One of these instruments is the Mother-Generated Index which is a subjective self-administered instrument. The difficulty and complexity of answering to this instrument has limited its use (20). Two other instruments for postpartum QOL assessment are the Maternal Postpartum QOL questionnaire and the Postpartum QOL questionnaire $(6,21)$. To the best of our knowledge, none of these instruments include dimensions on women's satisfaction with postpartum transition and mother-infant bonding. Therefore, simple but comprehensive instruments are needed for careful postpartum QOL assessment. The present study was conducted to fill this gap. The aim of the study was to develop the Maternal Postpartum Quality of Life Instrument (MPQOLI) and assess its psychometric properties.

\section{Materials and Methods}


This methodological study was conducted from June 2019 to April 2020 using an exploratory sequential mixed-method design. The study was conducted in two main phases, namely MPQOLI development and MPQOLI psychometric evaluation.

\section{Phase 1: MPQOLI development}

The primary draft of MPQOLI was developed using the steps recommended by Waltz et al. (22). Initially, a qualitative study was conducted using the conventional content analysis approach recommended by Graneheim and Lundman (23) in order to explore the concept of postpartum QOL and its dimensions. Participants were twenty postpartum women who were recruited purposefully and with maximum variation in terms of their age, educational level, financial status, route of delivery, type of infant feeding, number of children, and infant's gender and age. Inclusion criteria were age over eighteen, no severe physical or mental disorder such as depression, and a healthy infant with an age of 1-6 weeks. Data were collected through semi-structured interviews continued up to data saturation and were analyzed through conventional content analysis. The items of MPQOLI were developed using the findings of the qualitative study and the existing literature on postpartum QOL. Items were revised in a panel of experts consisted of the study authors and the primary MPQOLI was developed with 57 items.

\section{Phase 2: Psychometric assessment}

In this phase, the psychometric properties of MPQOLI, namely face, content, and construct validity as well as reliability, were assessed. Figure 1 shows the different steps of psychometric evaluation.

\section{Assessment of face validity}

\section{Figure 1}

Twenty postpartum women qualitatively and quantitatively assessed the face validity of MPQOLI. In qualitative face validity assessment, women commented on the comprehensibility of the items and responded four questions of the COSMIN methodology regarding the face validity of the items. These four questions were, "Was there any difficulty in comprehending the items?", "Was there any item you did not want to answer?", "Was there any topic related to your birth which had not been addressed in the instrument?", and "Was there any item in the instrument which was not related to the postpartum period?" (24).MPQOLI was revised according to their comments.

The quantitative assessment of face validity was performed by calculating item impact score. The same women were asked to rate the importance of each item on a five-point scale from 1("Unimportant") to 5 ("Very important"). Then, the impact score of each item was calculated through multiplying the frequency of participants scored that item 4 or 5 by the mean importance score of that item. Items with impact scores greater than 1.5 were considered appropriate $(25,26)$.

\section{Assessment of content validity}

The content validity of MPQOLI was qualitatively and quantitatively assessed by twenty experts in reproductive health $(n=10)$, instrument development $(n=2)$, obstetrics and gynecology $(n=2)$, psychology $(n=2)$, nutrition $(n=1)$, midwifery $(n=2)$, and nursing $(n=$ 1). For the qualitative assessment, they were asked to comment on the difficulty, wording, grammar, and comprehensibility of the items. MPQOLI was revised according to their comments.

For the quantitative assessment, experts were asked to comment on the essentiality and the relevance of each item on a three- and a four-point scale, respectively. Essentiality rating scores were used to calculate content validity ratio (CVR) using this formula: $C V R=$ 
$\left(N_{e}-N / 2\right) /(N / 2)$. Based on the Lawshe's table and the number of experts, items with CVR values equal to or greater than 0.42 were considered appropriate (25). On the other hand, relevance rating scores were used to calculate the content validity index (CVI) of each item through dividing the number of experts who had scored that item 3 or 4 by the total number of experts. Items with CVI values greater than 0.79 were considered appropriate, items with CVI values equal to $0.7-0.79$ were revised, and items with CVI values less than 0.7 were excluded (27). Modified Kappa statistic was also calculated for each item and items with Kappa values greater than 0.7 were considered appropriate (26).

\section{Item analysis}

After the assessment of face and content validity, 32 eligible women completed MPQOLI. Their data were used to calculate the Cronbach's alpha of the instrument and its items. Considering coefficients of correlation between item scores and total MPQOLI score as well as the changes of total Cronbach's value with exclusion of each item, poor items were determined and excluded. Moreover, items with a difficulty index less than 0.2 or more than 0.9 were respectively interpreted as very simple and very difficult and were excluded (28).

\section{Assessment of construct validity}

Construct validity was assessed through exploratory factor analysis (EFA), confirmatory factor analysis (CFA), and convergent and discriminant validity assessments. Sample size for factor analysis was calculated based on the 5-10 participants per item rule (29). In total, 700 postpartum women were invited to the study through personal telephone contact. Subsequently, 390 postpartum women were purposefully recruited from twenty healthcare centers in Tehran, Iran, to complete MPQOLI for EFA. Inclusion criteria were age over eighteen, ability to read and write, a healthy infant aged 1-6 weeks, no known physical or mental disorder, no disability, and a score less than 13 for the Edinburg Postnatal Depression Scale (EPDS). Participants completed MPQOLI and EPDS either online or in-person. EFA was performed using the SPSS software (v. 26.0). Sample adequacy was determined through the Kaiser-Meyer-Olkin (KMO) and the Bartlett's tests. A KMO value greater than 0.7 was interpreted as adequate sample (30). Latent factors were extracted through the maximum likelihood estimation with promax rotation and Horn's parallel analysis (31). Factor loading values greater than 0.3 and eigenvalues greater than 1 were considered appropriate $(32,33)$.

For CFA, 201 eligible women were purposefully recruited to complete MPQOLI either online or in-person. The population, setting, sampling method, sample size calculation, and inclusion criteria for CFA were the same as EFA. CFA was performed through the AMOS software (v. 24). Model fitness was assessed using the following fit indices: root mean score error of approximation (RMSEA), Chi-square $(\chi 2)$, minimum discrepancy function divided by degree of freedom (CMIN/DF), comparative fit index (CFI), parsimonious comparative fit index (PCFI), parsimonious normal fit index (PNFI), and incremental fit index (IFI).

Convergent and discriminant validity were assessed through the Fornell and Larcker's method and by calculating average variance extracted (AVE), maximum shared squared variance (MSV), and composite reliability (CR). An AVE value greater than 0.5 shows acceptable convergent validity and an AVE value greater than MSV shows acceptable discriminant validity (34).

\section{Assessment of reliability}

The reliability of MPQOLI was assessed by calculating Cronbach's alpha, McDonald's omega, $\mathrm{CR}$, average inter-item correlation (AIC), and coefficient H (35). Stability was assessed by calculating test-retest intraclass correlation coefficient (ICC) which was estimated through the two-way mixed effects and with a confidence level of 95\%. Moreover, standard error of 
measurement (SEM) and the minimum detectable change (MDC) were calculated in absolute stability assessment as criteria for responsiveness (36). SEM was calculated through the $S E M=S D \sqrt{1}-I C C$ formula, where $S D$ was the standard deviation of the sum values obtained in the test and the retest phases. MDC was also calculated through the $M D C=S E M \times Z \times \sqrt{2}$ formula, where $Z$ was 1.96 and the level of confidence was 0.95 . The relative amount of random measurement error was also calculated through this formula, $M D C \%=(M D C /$ Mean $) \times 100$. An MDC\% value of less than $30 \%$ is acceptable and a value of less than $10 \%$ is excellent $(36,37)$.

\section{Sensitivity}

Sensitivity was assessed through hypothesis testing (38). The hypothesis was "Postpartum QOL has significant relationship with the type of infant feeding". This hypothesis was tested using the one-way analysis of variance.

\section{Interpretability}

Interpretability was assessed by calculating minimal importance change (MIC) through the $M I C=0.5 \times S D$ of the $\Delta$ score formula. An MIC greater than MDC confirms interpretability $(39,40)$.

\section{Feasibility}

We attempted to use robust methods for psychometric assessment and maintain only the most important items in the instrument in order to develop an instrument with an acceptable number of items and short response time $(39,41)$.

\section{Scoring}

MPQOLI items are scaled on a five-point Likert scale as follows: 1: "None"; 2: "Little"; 3: "Moderate"; 4: "Much"; and 5: "Very much". Items 12, 25, and 28 are reversely scaled. The possible total score of the instrument is $16-80$ with higher scores showing better QOL. This score was changed into a $0-100$ scale through the following formula,

$$
\text { MPQOLI score }=\frac{(\text { Raw score }- \text { The lowesst raw score })}{(\text { The lowesst raw score }- \text { The highest raw score })} \times 100
$$

\section{Outliers, normal distribution of the data, and missed data}

The frequency of the missed data in the final analysis was zero because the instrument for online answering had forced responses (with asterisk) and missed data in the instruments of those participants who answered the instrument in-person were determined through making telephone contact with them and asking them to provide response to non-responded items. The normal distribution of the data was assessed using both univariate and multivariate distribution testing. Multivariate outliers were determined through the Mahalanobis d-squared $(\mathrm{P}<0.001)$ and multivariate normality was tested using the Mardia coefficient. A Mardia coefficient value of less than 8 was considered acceptable (42).

\section{Ethical considerations}

The Ethics Committee of Shahid Beheshti University of Medical Sciences, Tehran, Iran, approved this study (code: IR.SBMU.RETECH.REC.1397.1343). Necessary permissions for the study were obtained from the authorities of the university and the study setting. Participants received clear information about the study aim and the confidentiality of their data and provided informed consent for participation. Free online midwifery counseling was offered to participants for one year in order to increase response rate. 


\section{Results}

The findings of the MPQOLI development phase

The conventional content analysis of the interviews with twenty postpartum women resulted in the development of 1009 primary codes which were reduced to 113 final codes in 41 subcategories, sixteen main categories, and six main themes. Based on these findings, postpartum QOL was defined as a relative and multidimensional concept affected by women's perceptions and experiences of the available family and social support, maternal and neonatal psycho-emotional conditions, maternal health status, breastfeeding and neonatal care status, socioeconomic status, and change in the rhythm of life according to maternal roles. These findings were used to develop the primary 57-item MPQOLI.

\section{The findings of the MPQOLI psychometric assessment phase}

\section{Assessment of face validity}

Some items were revised in the qualitative assessment of face validity. Then, the quantitative assessment of face validity showed that the impact scores of the items were 3.75-5 and hence, none of the items were excluded.

\section{Assessment of content validity}

Eight items were deleted due to low CVR or CVI values and six items were revised. The CVR, CVI, and Kappa values of the remaining 49 items were equal to or greater than $0.37,0.79$, and 0.77, respectively. The average scale-level CVI (S-CVI/Ave) was also 0.92.

\section{Item analysis}

Thirty-two postpartum women completed the MPQOLI and their data were used for item analysis. The total Cronbach's alpha of the 49-item MPQOLI was 0.857. Considering the coefficients of correlation between the total score of MPQOLI and the score of each item as well as the changes in the total Cronbach's alpha with the exclusion of each item, eighteen poor items were deleted and 31 items remained. All pairwise inter-item correlation coefficients were less than 0.7 .

\section{Assessment of construct validity}

The mean age of the 590 postpartum women who were studied in EFA and CFA was $29.67 \pm 5.09$ years. The gender of participants' newborns was male in $52.2 \%$ of cases and female in $47.8 \%$ of cases. Most participants had average financial status $(62.7 \%)$ and diploma degree or higher $(71 \%)$ and had undergone Cesarean section (58.5\%). Type of feeding was breastfeeding in 54\% of cases, combined breastfeeding and bottle-feeding in $37.6 \%$ of cases, and bottle-feeding in $8.4 \%$ of cases.

In EFA, KMO statistic was 0.807 and the Bartlett's test value was $2302.889(\mathrm{P}<0.001)$. In $\mathrm{EFA}$, fifteen items were deleted and the remaining sixteen items were loaded on five factors which explained $53.26 \%$ of the total variance. Horn's parallel analysis also extracted the same five factors. These five factors were labeled perceived support, sexual relationship, bonding with newborn, breastfeeding and newborn care, and satisfaction with postpartum transition (Table 1).

In CFA, CMIN/DF was 2.192, RMSEA was 0.057, $\chi 2$ was 206.087, PCFI was 0.738, PNFI was 0.705 , CFI was 0.942 , and IFI was 0.943 (Table 2). These findings confirmed the five- 
factor structure of the sixteen-item MPQOLI. Figure 2 shows this structure and the coefficients of the pairwise correlations between MPQOLI items and dimensions.

\section{Table1:}

\section{Table 2:}

\section{Figure 2:}

\section{Assessment of convergent and discriminant validity}

The AVE values of all factors were more than 0.5 and MSV values in all factors were less than AVE (Table 3). These findings confirmed the acceptable convergent and discriminant validity of MPQOLI.

\section{Assessment of reliability}

Internal consistency assessment showed that the Cronbach's alpha, McDonald's Omega, CR, and coefficient $\mathrm{H}$ values of all factors were greater than 0.7 (Table 3). Moreover, AIC values were $0.438-0.756$ (Table 3).

\section{Table 3:}

Relative stability assessment showed that the ICC of MPQOLI was 0.919 (95\% CI: 0.8650.954; P < 0.001). Absolute stability assessment also showed that SEM was 1.71. MDC and MDC\% values were also 4.72 and $8.69 \%$, respectively.

\section{Sensitivity}

The results of the one-way ANOVA analysis of variance showed at least one significant difference among women from different groups of feeding type respecting their postpartum QOL $(\mathrm{P}<0.001)$. Post hoc analysis revealed that the QOL of women who bottle-fed their neonates was significantly less than those who provided their neonates with breastfeeding or combined breastfeeding and bottle-feeding $(\mathrm{P}<0.001)$.

\section{Interpretability}

MIC and MDC values were 5.8 and 4.73, respectively. The greater value of MIC compared with MDC confirmed the good interpretability of MPQOLI.

\section{Feasibility}

MPQOLI has sixteen simple and short items in all important dimensions of postpartum QOL. The response time of the instrument is $8-10$ minutes in the paper-and-pencil version and five minutes in the online version.

\section{Discussion}

This study was conducted to develop MPQOLI and assess its psychometric properties. Findings revealed that the sixteen-item MPQOLI has acceptable validity and reliability and its five main factors are perceived support, sexual relationships, bonding with newborn, breastfeeding and newborn care, and satisfaction with postpartum transition. These factors are discussed in what follows.

The perceived support factor of MPQOLI, which explained the greatest amount of variance, has four items on husband's attentiveness, husband's understanding of the new conditions, 
intimacy with husband, and husband's engagement in newborn care. A former study showed that socio-emotional help and support were among the significant predictors of depression, stress, and QOL among pregnant women (43). Another study reported a significant positive relationship between postpartum QOL and husband's support (44). Similarly, a study found that spousal support and good marital relationship were significant factors contributing to the improvement of postpartum QOL (44). Support is a key component of almost all QOL-related instruments such as the Maternal Postpartum QOL questionnaire, the Postpartum QOL questionnaire, and the WHOQOL-BREF $(6,21,45)$.

The sexual relationship factor of MPQOLI has three items on problems in sexual relationships including limitations in sexual intercourse and its relevant physical and mental problems. A study showed that sexual dysfunction in the postpartum period can negatively affect women's QOL and highlighted that despite their high prevalence and significant effects on marital relationships, sexual problems in the postpartum period are often underreported (46). Some existing instruments for postpartum QOL assessment include one or more items on sexual relationship, while MPQOLI includes a main dimension on this aspect of QOL.

The bonding with newborn factor of MPQOLI has three items on women's feelings for motherbecoming and feelings of power and calmness in relation to their newborn. Mother-newborn bonding is highly affected by women's parental skills and can reduce their stress and improve their QOL. Therefore, quality education should be provided to postpartum women in order to improve their skills, their bonding with their newborns, and thereby, their QOL (47). A systematic review revealed a wide knowledge gap regarding the relationship of maternal-fetal attachment and early postpartum bonding with maternal mental health and highlighted the necessity of developing valid instruments for postpartum QOL assessment (48). MPQOLI is the only postpartum QOL assessment instrument which includes items on bonding.

The breastfeeding and newborn care factor has three items on women's feelings about breast milk adequacy, self-confidence in newborn care, and adequate skills for newborn care. A former study showed that women whose newborns had good sleep and feeding had better mental health and QOL scores compared with other women (49). Breastfeeding is a significant factor contributing to successful mother-newborn bonding (50). Moreover, women with lower levels of prenatal and postnatal anxiety can more effectively care for their newborns, have better QOL, and have higher mental health status (50). Breastfeeding and newborn care are significant factors in postpartum QOL. Hence, they should be addressed in postpartum QOL assessment instruments. However, some of these instruments do not incorporate them as a distinct dimension.

The satisfaction with postpartum transition factor has three items on maternal satisfaction with the time she spends for her husband, level of recreational activities with newborn, and relationships with friends and relatives. Childbirth significantly changes couple's life and causes them some levels of stress in marital relationships (51). This stress makes women establish stronger relationships with their husbands and others and achieve higher levels of personal development and maturity (51). The most important sources of support in the postpartum period are family, friends, and colleagues (52). Certainly, any factor which improves postpartum satisfaction can improve QOL. Nonetheless, none of the existing postpartum QOL assessment instruments include dimensions on satisfaction with postpartum transition.

The MDC\% value of MPQOLI was 4.72 which is less than $10 \%$ and is interpreted as excellent (36,37). The SEM value of MPQOLI was also 1.71 .

Unlike other postpartum QOL assessment instruments, MPQOLI was developed based on almost all criteria of the COSMIN methodology for validity assessment and advanced psychometric assessment methods and has greater focus on the specific aspects of postpartum QOL. Moreover, the construct validity of MPQOLI was assessed through EFA, parallel 
analysis, and CFA, its reliability was assessed through Cronbach's alpha, test-retest stability, absolute stability, McDonald's Omega, AIC, CR, and coefficient H, and its sensitivity, responsiveness, interpretability, and feasibility were assessed through different methods. However, studies into the development and the psychometric assessment of the MotherGenerated Index (53), the Maternal Postpartum QOL questionnaire, and the Postpartum QOL questionnaire $(6,21)$ just provided information about some aspects of psychometric assessment. Moreover, compared with these instruments, the psychometric properties of MPQOLI were assessed in larger samples of postpartum women. MPQOLI also has fewer items and shorter response time compared with the existing postpartum QOL assessment instruments.

\section{Conclusion}

The sixteen-item MPQOLI has acceptable validity and reliability for postpartum QOL assessment. Therefore, it can be used as a simple and short instrument for the assessment of postpartum QOL in different settings. Data obtained through the application of MPQOLI can be used to develop appropriate interventions for improving QOL and preventing complications among postpartum women.

\section{Recommendations}

Future studies are recommended to use MPQOLI for postpartum QOL assessment and assess its psychometric properties in different cultures and communities.

\section{Abbreviations}

AIC: Average Inter Correlation

AGFI: Adjusted Goodness of Fit Index

AVE: average variance extracted

CFA: confirmatory Factor Analysis

CVR: Content Validity Ratio

CVI: Content Validity Index

CFI: Comparative Fit Index

CR: Composite reliability

CMIN/DF: Minimum Discrepancy Function by Degrees of Freedom Divided

EFA: Exploratory Factor Analysis

EPDS: Edinburgh Postnatal Depression Scale

H: Coefficient $H$

ICC: intra-class correlation coefficient

IFI: incremental fit Index

I-CVI: Item Content Validity Index

KMO: Kaiser-Meyer-Olkin Index

MPQOLI: The Maternal Postpartum Quality of Life Instrument

MAPP-QOL: Maternal Postpartum Quality Life Questionnaire

MSV: Maximum Shared Squared Variance

MGI: Mother-Generated Index

NFI: Normed Fit Index

PCFI: Parsimonious Comparative Fit Index

PNFI: Parsimonious Normal fit Index

PQOL: Postpartum Quality of Life

QOL: Quality of Life

RMSEA: Root Mean Square Error of Approximation

SEM: Standard Error of Measurement

SRMR: Standardized Root Mean Square Residual 


\section{SCVI/Ave: Scale Content Validity Index/Average}

\section{Declarations:}

\section{Ethics approval and consent to participate:}

After introducing the study, postpartum women voluntarily completed MPQOLI. The study objectives were explained, and participants were assured of the confidentiality of all data. All participants signed the consent forms. Code of Ethics received from Shahid Beheshti University of Medical Sciences: IR.SBMU.RETECH.REC.1397.1343

\section{Participate:}

The participants read the written consent form before filling in the questionnaire. After being introduced to the study, the postpartum women voluntarily completed the Questionnaires. The study objectives were explained, and participants were assured of the confidentiality of all data.

\section{Consent for publication:}

Not applicable.

\section{Availability of data and materials:}

The datasets used and/or analyzed during the current study are available via contacting the corresponding author on reasonable request.

\section{Competing interests:}

The authors declare that they have no competing interests.

\section{Funding:}

Not applicable.

\section{Authors' contributions}

TM-G, NK, HSH, MA-D and MN substantially contributed to the paper's conception and design. They were involved in drafting the manuscript, revising it critically for intellectual content, and giving the final approval of this version of the manuscript to be published.

\section{Acknowledgement}

This article was extracted from a PhD dissertation in reproductive health in Shahid Beheshti University of Medical Sciences, Tehran, Iran. The authors would like to thank all participating women and all staff of the study setting for their help and support. 


\section{References}

1. Larkin P, Begley CM, Devane D. Women's experiences of labour and birth: an evolutionary concept analysis. Midwifery. 2009;25(2):e49-59.

2. Knoema. childbirth in 2019. In 2020. Available from: https://knoema.com/atlas/topics/Demographics/Fertility/Number-of-births

3. Saisto T, Halmesmäki E. Fear of childbirth: a neglected dilemma. Acta Obstet Gynecol Scand. 2003;82(3):201-8.

4. Deniz C, Ayaz S. Factors causing stress in women with babies 0-3 months old and their coping styles. J Psychiatr Ment Health Nurs [Internet]. 2014 Sep [cited 2019 Jan 2];21(7):587-93. Available from: http://doi.wiley.com/10.1111/jpm.12119

5. Grylka-Baeschlin S, Meyer T, Lengler L, van Teijlingen E, Pehlke-Milde J, Gross MM. Postnatal quality of life - A content analysis of qualitative results to the MotherGenerated Index. Women and Birth. 2019 Apr 1;32(2):e229-37.

6. Zhou S-Z, Wang X-L, Wang Y. Design of a questionnaire for evaluating the quality of life of postpartum women (PQOL) in China. Qual Life Res [Internet]. 2009 May 25 [cited 2020 Jan 12];18(4):497-508. Available from: http://link.springer.com/10.1007/s11136-009-9466-2

7. Chinweuba AU, Okoronkwo IL, Anarado AN, Agbapuonwu NE, Ogbonnaya NP, Ihudiebube-Splendor CN. Differentials in health-related quality of life of employed and unemployed women with normal vaginal delivery. BMC Womens Health [Internet]. 2018 Dec 10 [cited 2018 Oct 17];18(1):13. Available from: https://bmcwomenshealth.biomedcentral.com/articles/10.1186/s12905-017-0481-0

8. McGregor JA, Camfield L, Woodcock A. Needs, Wants and Goals: Wellbeing, Quality of Life and Public Policy. Appl Res Qual Life [Internet]. 2009 Jun 27 [cited 2018 Oct 16];4(2):135-54. Available from: http://link.springer.com/10.1007/s11482-009-9069-7

9. Sadat Z, Abedzadeh-Kalahroudi M, Kafaei Atrian M, Karimian Z, Sooki Z. The Impact of Postpartum Depression on Quality of Life in Women After Child's Birth. Iran Red Crescent Med J [Internet]. 2014 Feb 5 [cited 2020 Jan 12];16(2):e14995. Available from: http://ircmj.com/en/articles/16164.html

10. Tungchama F, Piwuna C, Armiya'u A, Maigari Y, Davou F, Goar S, et al. Independent socio-demographic and clinical correlates associated with the perception of quality of life of women with postpartum depressionin North-central, Nigeria. Int J Psychiatry Clin Pract. 2017 Oct 2;21(4):292-301.

11. Petrou S, Boulvain M, Simon J, Maricot P, Borst F, Perneger T, et al. Home-based care after a shortened hospital stay versus hospital-based care postpartum: an economic evaluation. BJOG An Int J Obstet Gynaecol [Internet]. 2004 Aug 1 [cited 2018 Oct 25];111(8):800-6. Available from: http://doi.wiley.com/10.1111/j.14710528.2004.00173.x

12. Papamarkou M, Sarafis P, Kaite CP, Malliarou M, Tsounis A, Niakas D. Investigation of the association between quality of life and depressive symptoms during postpartum period: a correlational study. BMC Womens Health [Internet]. 2017 Dec 21 [cited 2020 Jan 12];17(1):115. Available from: https://bmcwomenshealth.biomedcentral.com/articles/10.1186/s12905-017-0473-0

13. Ghazanfarpour M, Khadivzadeh T, Babakhanian M. Investigating the Relationship Between Sexual Function and Quality of Life in Menopausal Women. J Fam Reprod Heal [Internet]. 2016 [cited 2018 Oct 17];10(4):191-7. Available from: https://pdfs.semanticscholar.org/39df/e9afa72e8c752b31033678f058dd1b26c27e.pdf

14. Rezaei N, Tavalaee Z, Sayehmiri K, Sharifi N, Daliri S. The relationship between quality of life and methods of delivery: A systematic review and meta-analysis. Electron physician [Internet]. 2018 Apr 25 [cited 2020 Jan 7];10(4):6596-607. Available from: 
http://www.ephysician.ir/index.php/browse-issues/10/4/995-6596

15. Fontenele de Oliveira M, Parker L, Ahn H, Lívia Oliveira Catunda H, Braga Rodrigues Bernardo E, Fontenele de Oliveira M, et al. Maternal Predictors for Quality of Life during the Postpartum in Brazilian Mothers. Health (Irvine Calif) [Internet]. 2015 [cited 2018 Oct 25];7(7):371-80. Available from: http://repositorio.ufc.br/bitstream/riufc/15210/1/2015_art_mfoliveira.pdf

16. Taheri-Kalani F, Mami S, Direkvand-Moghadam A, Kaikhavani S, Delpisheh A. Comparison of the effect of delivery type on the quality of life in women attending to health centers of Ilam and Aivan during 2013. J Shahrekord Univ Med Sci [Internet]. 2014 [cited 2018 Oct 17];16(2):90-6. Available from: http://eprints.skums.ac.ir/3711/

17. Akbarzadeh M, Toosi M, Zare N, Sharif F. Effect of Relaxation Training to Pregnant Mothers on Quality of life and Postpartum Blues. Knowl Heal J [Internet]. 2012 [cited 2018 Oct 17];7(2):83-8. Available from: http://www.sid.ir/En/Journal/ViewPaper.aspx?ID=310382

18. CADTH. Guidelines for the Economic Evaluation of Health Technologies: Canada [Internet]. bases.bireme.br. 2017 [cited 2018 Oct 17]. Available from: http://bases.bireme.br/cgi-

bin/wxislind.exe/iah/online/?IsisScript=iah/iah.xis\&src=google \&base=REPIDISCA\&l ang=p\&nextAction=lnk\&exprSearch=173610\&indexSearch=ID

19. Bahrami N, Simbar M, Bahrami S. The effect of prenatal education on mother's quality of life during first year postpartum among Iranian women: A randomized controlled trial. Int J Fertil Steril [Internet]. 2013 [cited 2018 Oct 26];7(3):169-74. Available from: https://www.ncbi.nlm.nih.gov/pmc/articles/PMC3914493/

20. Symon A, MacKay A, Ruta D. Postnatal quality of life: a pilot study using the MotherGenerated Index. J Adv Nurs [Internet]. 2003 Apr [cited 2020 Jan 12];42(1):21-9. Available from: http://www.ncbi.nlm.nih.gov/pubmed/12641808

21. Hill PD, Aldag JC, Hekel B, Riner G, Bloomfield P. Maternal Postpartum Quality of Life Questionnaire. J Nurs Meas [Internet]. 2006 [cited 2020 Jan 12];14(3):205-20. Available from: http://www.ncbi.nlm.nih.gov/pubmed/17278340

22. Waltz CF, Strickland OL, Lenz ER. Measurement in nursing and health research. Springer publishing company; 2010.

23. Graneheim UH, Lundman B. Qualitative content analysis in nursing research: Concepts, procedures and measures to achieve trustworthiness. Nurse Educ Today. 2004;24(2):105-12.

24. Terwee CB, Prinsen CAC, Chiarotto A, Westerman MJ, Patrick DL, Alonso J, et al. COSMIN methodology for evaluating the content validity of patient-reported outcome measures: a Delphi study. Vol. 27, Quality of Life Research. Springer International Publishing; 2018. p. 1159-70.

25. Lawshe CH. A quantitative approach to content validity. Pers Psychol. 1975;28(4):56375.

26. Denise F. Polit CTB. Nursing Research: Generating and Assessing Evidence for Nursing Practice. 2017.

27. Hanh VTX, Guillemin F, Cong DD, Parkerson Jr GR, Thu PB, Quynh PT, et al. Health related quality of life of adolescents in Vietnam: cross-cultural adaptation and validation of the Adolescent Duke Health Profile. J Adolesc. 2005;28(1):127-46.

28. Thorndike RM, Cunningham GK, Thorndike RL, Hagen EP. Measurement and evaluation in psychology and education. Macmillan Publishing Co, Inc; 1991.

29. Kellar SP, Kelvin EA. Munro's statistical methods for health care research. Wolters Kluwer Health/Lippincott Williams \& Wilkins,; 2013.

30. Eba. Reliability and validity of the persian version of templer death anxiety scale- 
extended in veterans of Iran-Iraq warfare. Iran J psychiatry Behav Sci. 2014;8(4):29.

31. Çokluk Ö, Koçak D. Using Horn's parallel analysis method in exploratory factor analysis for determining the number of factors. Kuram ve Uygulamada Egit Bilim [Internet]. 2016 [cited 2020 Jan 22];16(2):537-52. Available from: www.estp.com.tr

32. Collett L-J, Lester D. The fear of death and the fear of dying. J Psychol. 1969;72(2):17981.

33. Colton D, Covert RW. Designing and constructing instruments for social research and evaluation. John Wiley \& Sons; 2007.

34. Hair JF, Black WC, Babin BJ, Anderson RE. Multivariate data analysis seventth edition. Explor Data Anal Bus Econ. 2013;

35. Hancock GR. Rethinking construct reliability within latent variable systems. Struct Equ Model Present Futur. 2001;195-216.

36. Ebadi A of scale development in health sciences. principles of scale development in health science. 2017. 28 p.

37. Wu C, Chuang L, Lin K, Hong W. Responsiveness, minimal detectable change, and minimal clinically important difference of the Nottingham Extended Activities of Daily Living Scale in patients with improved performance after stroke rehabilitation. Arch Phys Med Rehabil. 2011;92(8):1281-7.

38. Polit DF. Assessing measurement in health: Beyond reliability and validity. Int J Nurs Stud. 2015;52(11):1746-53.

39. Mokkink LB, Terwee CB, Patrick DL, Alonso J, Stratford PW, Knol DL, et al. The COSMIN checklist for assessing the methodological quality of studies on measurement properties of health status measurement instruments: An international Delphi study. Qual Life Res. 2010 May;19(4):539-49.

40. Esposito Vinzi V, Chin WW, Henseler J, Wang H. Handbook of partial least squares: Concepts, methods and applications. Heidelberg, Dordrecht, London, New York: Springer; 2010.

41. Sajadi SA, Ebadi A, Moradian ST, Akbari R. Designing and Validation of HealthRelated Quality of Life Inventory for Family Caregivers of Hemodialysis Patients. Int J Community Based Nurs Midwifery. 2020;8(2):164.

42. Ebadi A, Taghizadeh Z, Montazeri A, Shahvari Z, Tavousi M, Bagherzadeh R. Translation, development and psychometric properties of health related measures-Part 2: construct validity, reliability and responsiveness. Payesh (Health Monit. 2017;16(4):445-55.

43. Xiaowen W, Guangping G, Ling Z, Jiarui Z, Xiumin L, Zhaoqin L, et al. Depression and anxiety mediate perceived social support to predict health-related quality of life in pregnant women living with HIV. AIDS Care. 2018;30(9):1147-55.

44. Akbay AS, Tasci-Duran E. How Does Spousal Support Affect Women'S Quality Of Life In The Postpartum Period In Turkish Culture? 2018;

45. WEBSTER J, NICHOLAS C, VELACOTT C, CRIDLAND N, FAWCETT L. Validation of the WHOQOL-BREF among women following childbirth. Aust New Zeal J Obstet Gynaecol [Internet]. 2010 Apr [cited 2020 Jan 7];50(2):132-7. Available from: http://doi.wiley.com/10.1111/j.1479-828X.2009.01131.x

46. Rezaei N, Janani F, Sharifi N, Omidi F, Azadi A. Sexual Function and Quality of Life Among Postpartum Women: A Cross-Sectional Study. Int J Women's Heal Reprod Sci [Internet]. 2018 Jan 28 [cited 2020 Jan 13];6(3):307-12. Available from: http://ijwhr.net/text.php?id=358

47. Gharibi H, Sheidai A, Rostami CH. The Effectiveness of Parenting Skills Training on Attachment, Perceived Stress and Quality of Life in Mothers of Preschool Children. J Heal Care. 2017;18(4):292-305. 
48. McNamara J, Townsend ML, Herbert JS. A systemic review of maternal wellbeing and its relationship with maternal fetal attachment and early postpartum bonding. Hill B, editor. PLoS One [Internet]. 2019 Jul 25 [cited 2020 Jan 13];14(7):e0220032. Available from: http://dx.plos.org/10.1371/journal.pone.0220032

49. Triviño-Juárez JM, Nieto-Pereda B, Romero-Ayuso D, Arruti-Sevilla B, Avilés-Gámez B, Forjaz MJ, et al. Quality of life of mothers at the sixth week and sixth month post partum and type of infant feeding. Midwifery [Internet]. 2016 Mar 1 [cited 2018 Oct 17];34:230-8. Available from: https://www.sciencedirect.com/science/article/pii/S0266613815002867

50. Kenyhercz F, Kató S, Nagy BE. Health-related quality of life of premature infants at 2 years in relation to breastfeeding and maternal emotional state: a retrospective cohort study. Early Child Dev Care. 2019;1-11.

51. Siebert HM. The Transition to Parenthood: Change, Challenges, and Marital Satisfaction. University of South Dakota; 2011.

52. Xuereb RB, Abela A, Spiteri G. Early parenting-portraits from the lives of first-time parents. J Reprod Infant Psychol. 2012;30(5):468-82.

53. Symon A, MacDonald A, Ruta D. Postnatal Quality of Life Assessment: Introducing the Mother-Generated Index. Birth [Internet]. 2002 Mar 6 [cited 2020 Jan 12];29(1):40-6. Available from: https://onlinelibrary.wiley.com/doi/abs/10.1046/j.1523536X.2002.00154.X 


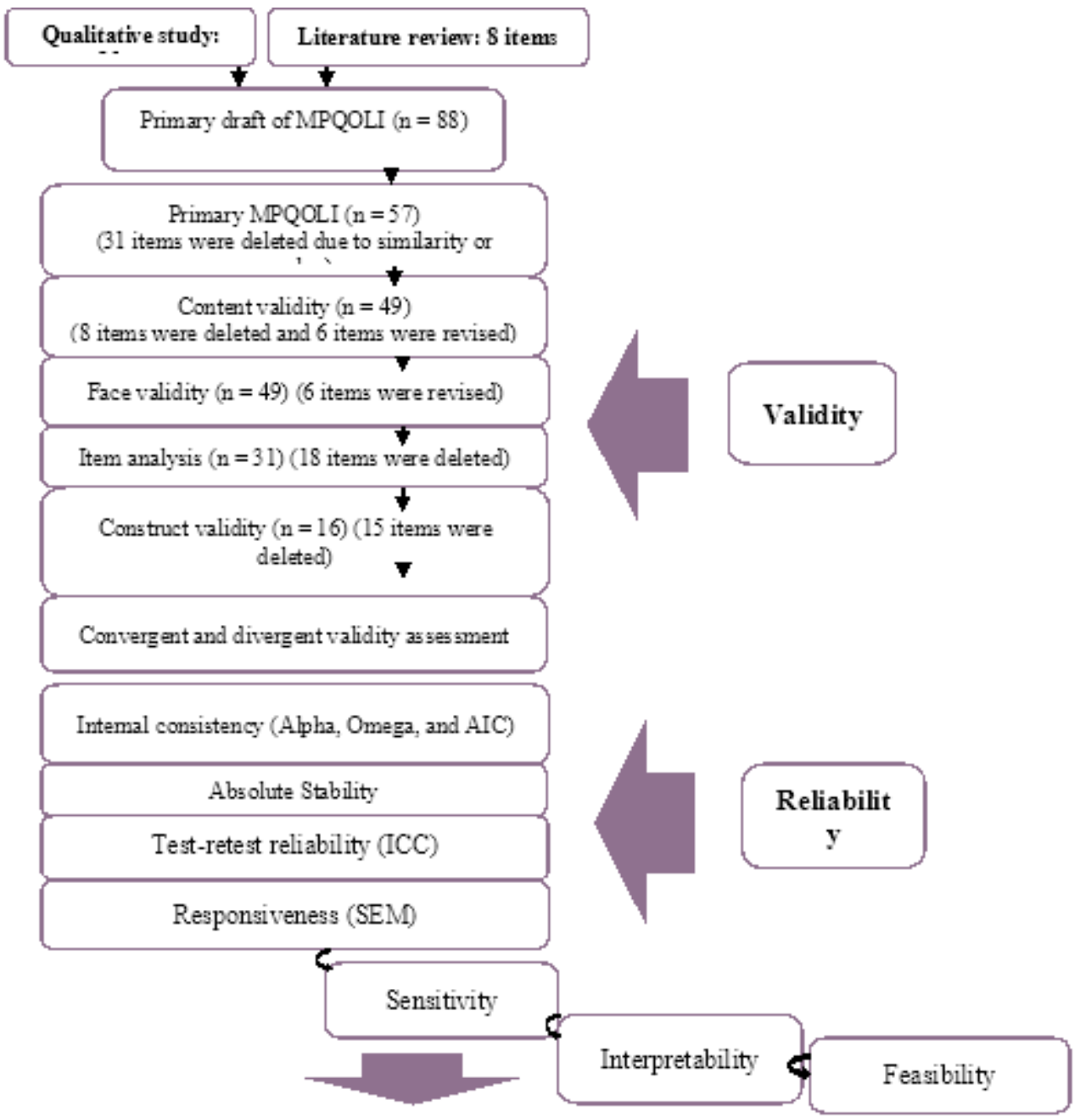

Maternal Postpartum Quality of Life Instrument (MPQOLI)

\section{Figure 1}

The flow chart of MPQOLI development and psychometric assessment 


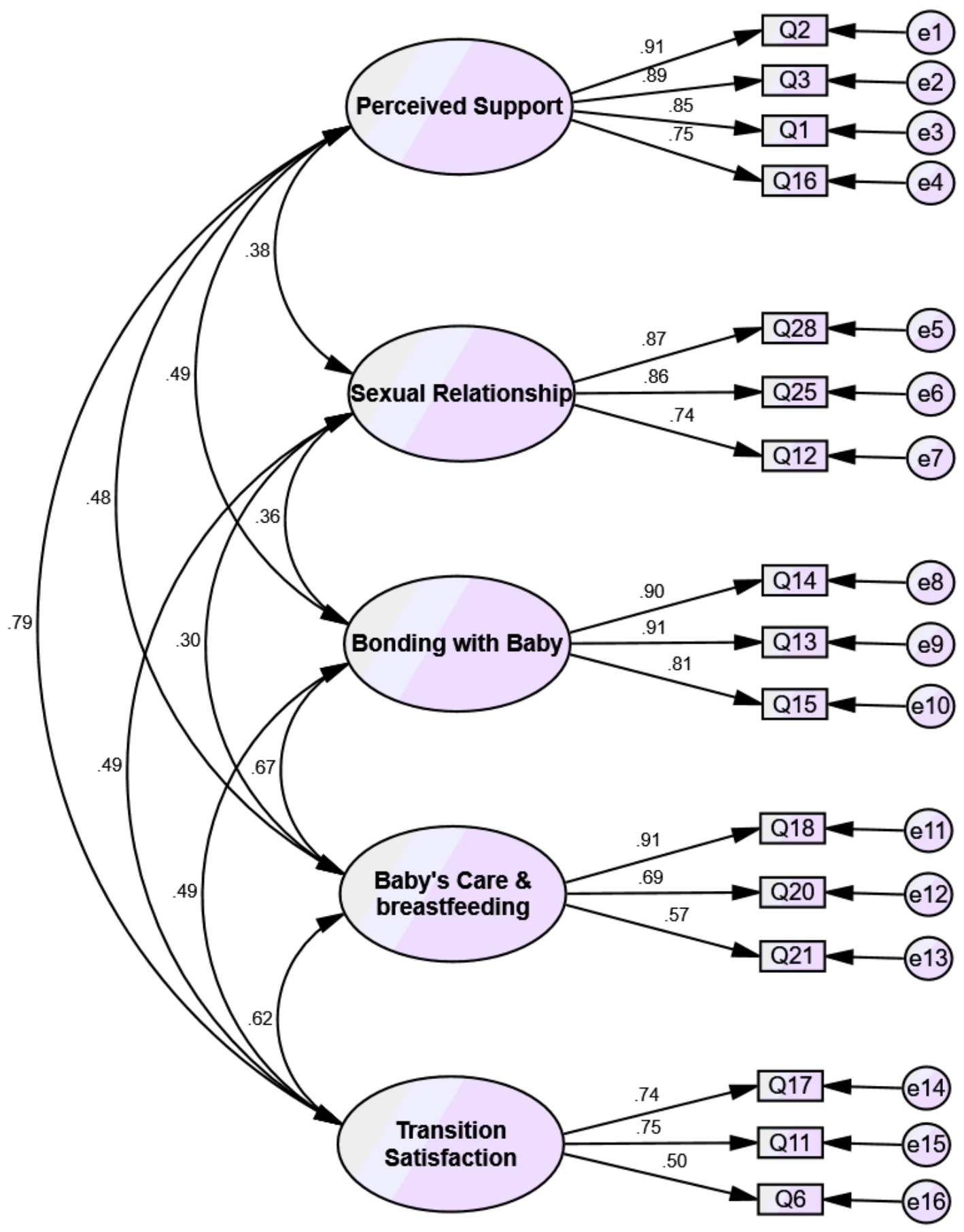

Figure 2

The final structure of MPQOLI confirmed in CFA

\section{Supplementary Files}

This is a list of supplementary files associated with this preprint. Click to download. 
- Additionalfile1.PERSIANversionofMPQOLI.docx

- Additionalfile2.ENGLISHversionOFMPQOLI.docx 